\title{
ANÁLISE COGNITIVA DO PROCESSO LEITOR NO RECONHECIMENTO DE PALAVRAS
}

\author{
Jussara Maria Oliveira de Araújo \\ Silvana Andrade Martins
}

\begin{abstract}
RESUMO
A leitura é uma aptidão difícil de ser desenvolvida, exigindo um extenso aprendizado. Nesta perspectiva, objetiva-se descrever e analisar as habilidades de reconhecimento de palavras, através do Modelo de Reconhecimento de Palavras, proposto por Ellis (1995). Os resultados obtidos contribuem para uma prática pedagógica mais eficiente na formaçáo da competência leitora.
\end{abstract}

PALAVRAS-CHAVE: reconhecimento de palavras; compreensão leitora; processos cognitivos.

\section{Introdução}

leitura é uma habilidade complexa, que exige do leitor o domínio de um
vasto aprendizado. Constitui-se de açóes direcionadas ao entendimento
do texto lido, que compreendem desde a decodificação das letras, pas-
sando pela identificação da informação, compreensão do texto, até a reflexão,
para que se estabeleçam associaçóes entre o texto e a percepção de mundo do
leitor. É um processo linguístico-cognitivo que exige do leitor o emprego de
conhecimentos gramaticais, culturais, sociais na interação com o texto.
Os vários estudos científicos sobre a leitura geralmente focalizam a pro-
núncia de palavras isoladas. No entanto, conforme adverte Ellis (1995, p. 16),
não se deve esquecer o fato de que a leitura envolve ler sentenças que, conec-
tadas, formam passagens de textos, com unidade, coerência e que transmitem
informaçôes, instruçôes, além de servirem de entretenimento, etc.


O processo leitor, de acordo com Ellis (1995, p. 19), desenvolve-se pela ativação de mecanismos cognitivos que envolvem o reconhecimento hábil das palavras. Alguns fatores exercem determinada influência, que pode ser positiva ou negativa, nesse processo. São eles: familiaridade, frequência, idade, repetição, sentido do texto e fator semântico.

Considerando tais fatores, o objetivo deste estudo é analisar o processo leitor relativo ao reconhecimento das palavras na leitura de alunos e professores de ensino médio. Para isso, norteia-se nos princípios teórico-metodológicos do Modelo de Reconhecimento de Palavras, proposto por Ellis (1995), ao considerar os resultados de várias pesquisas desenvolvidas por Fodor, 1983; Humphreys \& Bruce, 1989; Besner \& Humphreys, 1991.

Os modelos de reconhecimento de palavras buscam descrever os processos mentais que proporcionam ao leitor a identificação, compreensão e pronunciação de palavras escritas. Os mais recentes contam com a tecnologia da informática para simular aspectos próprios da mente humana, empregados no reconhecimento de palavras.

Andrew Ellis (1995), em seu livro Leitura, Escrita e Dislexia, apresenta um modelo funcional e simples, que ilustra alguns processos cognitivos envolvidos no reconhecimento de palavras escritas isoladamente. Estruturado em forma de diagrama, destaca os subsistemas cognitivos de reconhecimento de palavras, que abrangem desde a palavra escrita até a fala, os quais são: o sistema de análise visual, léxico de input visual, sistema semântico, léxico da produção de fala e nível do fonema.

A partir dos resultados desta pesquisa, realizada no contexto escolar, demonstra-se, como a leitura se processa, como a decisão lexical é feita pelo leitor e como os fatores supramencionados influenciam no reconhecimento de palavras.

A pesquisa desenvolveu-se junto a um grupo de 25 alunos do $1^{\circ}$ ano do Ensino Médio e entre 3 professores de Língua Portuguesa, de uma escola estadual, situada na zona Oeste da cidade de Manaus, estado do Amazonas. O procedimento para coleta de dados consistiu de registros de leituras individuais, executadas pelos participantes da pesquisa, de um texto em que somente a primeira e a última letras estavam na posição correta. Com isso, buscou-se verificar a velocidade, fluência e compreensão leitora. 
Os resultados obtidos auxiliam na discussão sobre os processos cognitivos ativados durante a leitura e contribuem para orientar uma prática pedagógica mais eficiente na perspectiva da formação das habilidades leitoras.

\section{Modelo de reconhecimento de palavras}

Há várias propostas de modelos de reconhecimento de palavras que buscam caracterizar os processos mentais que proporcionam ao leitor identificar, compreender e pronunciar palavras escritas. $\mathrm{O}$ modelo de Ellis (1995), utilizado neste estudo, busca decompor o processo de reconhecimento de palavras, identificando suas partes constitutivas e seu respectivo funcionamento.

O autor explica que certas combinações de letras reconhecidas como familiares tendem a ser reconhecidas com maior facilidade. Afirma que há diferenças de velocidade e acuidade na leitura de palavras familiares e entre não palavras, ou seja, palavras hipotéticas. Também explana a capacidade de reconhecer com mais facilidade palavras com alta frequência na língua, palavras repetidas no mesmo texto e palavras em contextos semânticos em que suas ocorrências são esperadas ou apropriadas, considerando a temática.

$\mathrm{O}$ autor ressalta que este modelo é simples e funcional e reúne e sintetiza outros modelos atuais. Apresentado em forma de diagrama, o sistema cognitivo proposto é formado por um conjunto de subsistemas semi-independentes, os quais são chamados de "módulos", em concordância com o conceito de modularidade, apresentado em Fodor (1983). Este conceito nos remete às diversas operaçóes circundantes ao reconhecimento de palavras, as quais são realizadas por diferentes módulos cognitivos, que envolvem o processo de leitura, podendo ser efetivados de forma distinta entre os indivíduos. O diagrama do Modelo de Ellis (1995) é apresentado pela figura 1 . 


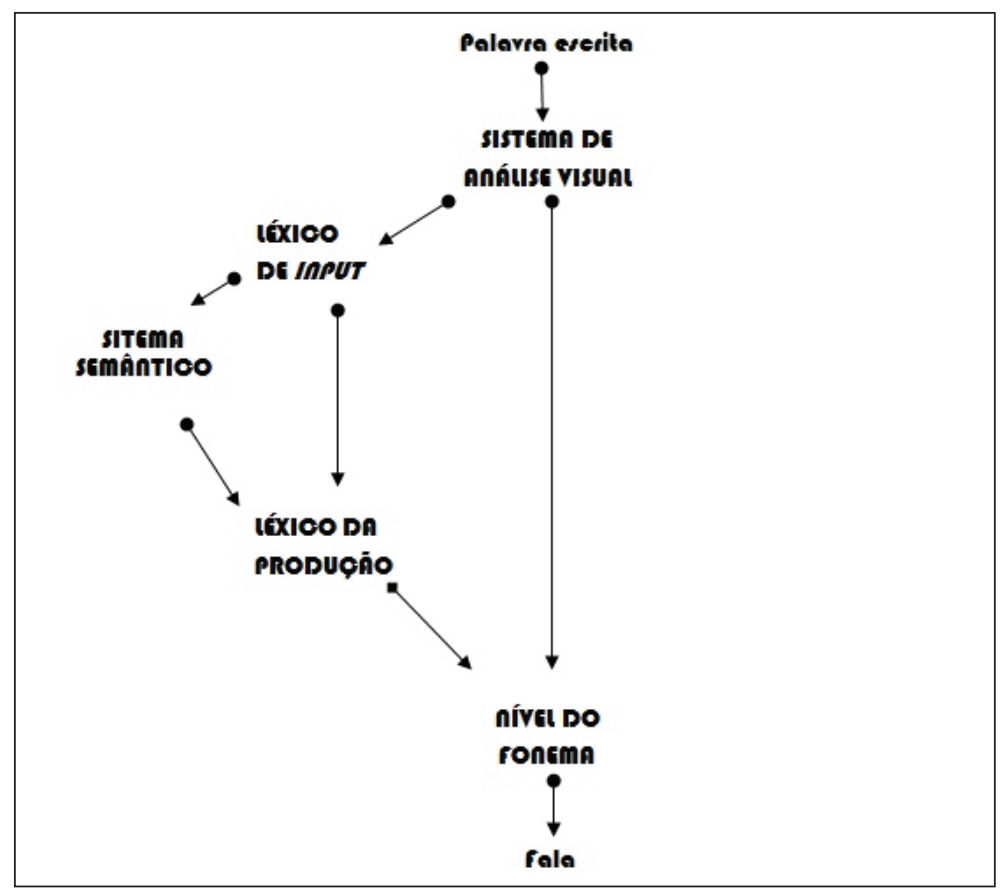

Figura 1: Modelo de Reconhecimento de Palavras Isoladas (Fonte: ELLIS, 1995, p. 31).

O sistema de análise visual, o primeiro módulo cognitivo apresentado no diagrama do Modelo de Reconhecimento de Palavras Isoladas (figura 1), é responsável pelo processamento de uma palavra escrita, tendo como função identificar as letras e verificar a posição de cada uma delas na palavra. Essa função deve ocorrer antes mesmo de o leitor acionar o subsistema de reconhecimento ou não da familiaridade da palavra.

O próximo módulo, o léxico de input visual, é onde o leitor identifica se a palavra em questão é ou não familiar a ele. Para metaforizar, esse subsistema cognitivo funciona como se fosse um armazém de palavras disposto em nossa mente, que abriga as representaçóes de todos os vocábulos que conhecemos, ou seja, daqueles que nos são familiares. Esse conteúdo depositado neste armazém forma o que se designa de unidades de reconhecimento de palavras. O léxico de input visual é ampliado pelo leitor por meio da familiarização com novas palavras escritas através da formação de novas unidades de reconhecimentos de palavras, que proporcionam novas associaçóes entre as unidades e 
as representações de significados e pronúncias. Contudo, é válido salientar que estes significados e pronúncias das palavras entram e se armazenam no léxico pelo ato leitor e não estão contidos nele mesmos.

O terceiro módulo é o sistema semântico, responsável pela compreensão textual. De acordo com Ellis (1995), para uma leitura ser completa, o objetivo a ser atingido deve ser o da compreensão do que está sendo lido e, para tanto, é necessário que se utilize o sistema semântico.

Em seguida, atua o sistema conhecido como léxico da produção da fala, que tem como função armazenar o conhecimento de como a palavra deve ser pronunciada. É importante realçar, nesse sentido, que em conformidade com o diagrama de Reconhecimento de Palavras, o léxico de input visual, onde estão armazenadas as unidades de reconhecimento de palavras, está conectado não só ao léxico de produção de palavras, que trata da pronúncia, mas também ao sistema semântico que remete ao significado da palavra que está sendo lida. Portanto, essa conexão é importante para efetivar a compreensão do texto.

O nível do fonema é o último módulo cognitivo, que entra em ação antes de completar a leitura da palavra, a fala. Ele é responsável por armazenar os fonemas no intervalo entre serem resgatados do léxico de produção da fala até o momento de serem articulados.

A leitura de uma palavra será facilitada se forem utilizadas as conexóes corretas entre o sistema semântico e o do léxico de produção de fala. Dentre os fatores que auxiliarão este acesso ao léxico de produção de fala está o fator de idade de aquisição de palavras. Quanto mais cedo esta palavra tiver sido armazenada no léxico de input visual do leitor, mais facilmente ela será recuperada no ato da leitura. Ressalta-se ainda que, no reconhecimento da palavra, pode ocorrer de o sistema semântico ser ignorado e, portanto, o leitor não compreenderá o que leu. Neste caso, a ligação, visualizada no diagrama, ocorre somente entre léxico de input visual e léxico de produção de fala.

\section{Fatores influentes no reconhecimento de palavras}

A fixação ou não de uma palavra e seu tempo de memorização não são eventos regulares. São ocorrências mutáveis de acordo com as capacidades de cada indivíduo e que sofrem a influência de fatores que intervêm nesse processo (ELLIS, 1995). 
A identificação desses fatores são alvos de pesquisas de abordagem na área da Psicolinguística, os quais contribuem para a construção de modelos de reconhecimento de palavras em atividades de leituras. A partir desta proposição, verificam-se os fatores que interferem positiva ou negativamente na habilidade de reconhecimento de palavras.

Reconhece-se que um assunto é familiar para uma pessoa, quando ela possui um acúmulo de conhecimento sobre ele. Semelhantemente, quando se trata de reconhecer a palavra durante a leitura, esse processo será favorecido pelo fator de familiaridade que consiste na facilitação de identificação de palavras, em conformidade com o grau de convivência que o leitor possui com uma determinada unidade lexical. Afinal, mesmo um leitor ávido, aquele que tem a leitura como uma atividade importante de sua rotina diária, sempre haverá vocábulos da língua que não lhe são tấo familiares quantos outros ou mesmo que lhe são desconhecidos, que não foram ainda armazenados pelo seu input visual.

A familiaridade, portanto, é o fator que se inicia com o contato com a palavra nova até que esta seja registrada na memória. Quando o leitor se propóe a aprender uma nova palavra, ele deverá desenvolver uma técnica de memorização para que esta deixe de ser estranha ao seu reconhecimento visu$\mathrm{al}$, associando a ela o seu respectivo significado e a pronúncia. $\mathrm{O}$ fator familiaridade é também um facilitador no momento em que estamos identificando imagens, em conformidade com Senna (2013).

Para a Psicologia Cognitiva, a aquisição de um novo vocábulo está relacionada com a formação de imagens internas da aparência, características acústicas e até mesmo do próprio significado deste vocábulo.

Uma variedade de técnicas experimentais tem sido usada para mostrar-se que, uma vez que uma palavra tenha-se tornado familiar, ela realmente é percebida mais facilmente do que uma palavra desconhecida.

Se a tarefa é simplesmente ler palavras [...] em voz alta, tão rapidamente quanto possível, as palavras familiares são lidas mais rapidamente [...] (ELLIS, 1995, p. 20). 
Portanto, quando existe representação visual interna para uma palavra na competência lexical de um determinado indivíduo, essa será lida com maior velocidade.

O fator de frequência está relacionado com o número de vezes em que as palavras ocorrem em uma determinada língua. Segundo Ellis (1995), estudos que verificam a influência desse fator no processo de reconhecimento de palavras demonstram que palavras ditas comuns na língua, isto é, aquelas de alta frequência, são mais facilmente reconhecidas que as menos frequentes.

Outro fator que influencia no reconhecimento de palavras é referente à idade em que o leitor tinha quando adquiriu o conhecimento de uma determinada unidade lexical. Gilhooly e Logie (1981), após pesquisas a esse respeito, apontam que palavras adquiridas nas idades mais tenras serão mais facilmente reconhecidas. Já as palavras que são tardiamente adquiridas podem exigir do leitor mais tempo para serem reconhecidas.

A repetição é outro fator que influencia no reconhecimento de palavras. Quando uma palavra é encontrada mais de uma vez em uma mesma atividade de leitura, esta será reconhecida com maior facilidade do que em uma situação contrária.

Esses fatores descritos, os de familiaridade, de frequência, de idade de aquisição e de repetição, foram verificados em estudos que testaram suas influências no reconhecimento de palavras isoladas de um contexto. Já o fator de sentido contextual foi proposto por pesquisas em que o leitor deveria identificar a palavra alvo em um contexto em que sua ocorrência fosse relevante, ou seja, prevista. Os resultados destes estudos revelam que há mais facilidade no reconhecimento da palavra alvo quanto maior for a relevância de sua ocorrência no contexto exibido. Porém, se o contexto for irrelevante para sua ocorrência, o seu reconhecimento se torna muito mais difícil, inclusive até mais do que se ela aparecesse isolada. Ellis (1995, p. 25) ratifica: "o contexto relevante facilitava a identificação da palavra, enquanto o contexto irrelevante inibia o reconhecimento.”.

O fator regularidade de correspondência entre ortografia e som também influencia no reconhecimento das palavras. Há palavras irregulares quanto a essa relação. A esse respeito, Ellis (1995, p. 26) explica: 
[...] houve um tempo na história da língua inglesa em que a ortografia de todas as palavras era um reflexo acurado de suas pronúncias. Também notamos que uma variedade de fatores conspiraram (sic) para que isso não mais ocorra. $\mathrm{O}$ resultado é que, atualmente, temos algumas palavras "regulares" que retêm uma boa combinação entre ortografia e pronúncia, mas também muitas palavras "irregulares", cuja ortografia e pronúncia divergem moderadamente.

Esse fator também ocorre em língua portuguesa. Nas palavras regulares, naquelas em que há correspondência entre a ortografia e o som, a pronúncia é facilitada. Do contrário, esta relação fica comprometida pela inconsistência, o que diminui a fluidez na leitura. Observa-se que esta afirmação possibilita relacionar este fator não somente com o reconhecimento de palavras, mas também com a fluência a ser exercida no momento da pronúncia em voz alta. Ao abordar esses fatores que influenciam no reconhecimento de uma palavra, é importante ressaltar que nem sempre eles agem de forma isolada, pois interagem entre si de diversas formas.

\section{Compreensão leitora no contexto escolar}

À escola, compete formar o leitor competente. Para isso, é importante, especialmente ao professor, conhecer como se processa a leitura, para melhor planejar sua prática pedagógica, a fim de propiciar o desenvolvimento da compreensáo leitora do aluno. Neste sentido, reafirma-se que a leitura, para ser completa, deve atingir o nível da compreensão textual e não apenas o da decodificação da palavra escrita. Esta última, no entanto, constitui-se na primeira fase do processo leitor, necessária para que se atinja o objetivo precípuo da leitura, que é a compreensão do texto.

Nesta perspectiva de estudo, emprega-se o Modelo de Reconhecimento de Palavras (Ellis, 1995), para verificar como os fatores descritos, em seção anterior, atuam como influenciadores na identificação das palavras. Considerando que no período escolar que compreende o ensino médio, os estudantes, por terem concluído a primeira etapa da educação básica, já devem ter um amadurecimento intelectual e familiaridade com a língua escrita, o que é cru- 
cial para a verificação dos fatores em questão. A amostra, no que se refere à participação discente, constitui-se de uma turma de 25 estudantes de uma escola estadual da zona Oeste da cidade de Manaus, capital amazonense. Foram 11 meninos e 14 meninas, que estão na faixa etária de 14 a 16 anos. Dentre esses, seis meninas e três meninos, num total de 9 alunos, foram reprovados em alguma série escolar.

Também, com o objetivo de verificar e comparar a habilidade leitora dos professores da disciplina Língua Portuguesa, dos quais se espera um alto domínio leitor, foram selecionados três professores para participarem desta experiência, sendo 1 homem e 2 mulheres. Todos são professores desta referida escola e lecionam para o ensino médio.

Com a finalidade de avaliar a habilidade e compreensão leitora, foi utilizado um texto como experimento, que versou sobre o tema leitura, que inclusive aborda o processo de reconhecimento de palavras. A sua primeira parte circula na Web e é bastante conhecida. A segunda parte é uma paráfrase de um parágrafo do livro Leitura, Escrita e Dislexia de Andrew Ellis (1995, p. 16). O fato de mesclar 'parte provavelmente familiar' e outra "inédita" para os leitores propicia a verificação do fator familiaridade. O texto foi escrito com um diferencial importante: apenas a primeira e última letras das palavras estão em suas posiçôes corretas, as demais letras estão fora de ordem, conforme se observa ${ }^{1}$ :

\begin{tabular}{|cc|}
\hline De aorcdo com uma peqsiusa & Etsa ifonrmaãço é itenrsesante \\
de uma uinrvesriddae ignlsea, & praa comrpeendemros \\
não ipomtra em qaul odrem as & o funocinaemnto dos prcoesoss \\
Iteras de uma plravaa etãso. & de aqsiçãuio da lteiura. \\
A úncia csioa iprotmatne é que & Eels expcalim cmoo \\
a piremria e útmlia Iteras etejasm & um Iteior háibl covnerte \\
no Igaur crteo. O rseto pdoe ser & as pvalaras esctrias em \\
uma bçguana ttaol, que vcoê & siifigncados de fala. \\
anida pdoe ler sem pobrlmea. & Uma Iteiura evonlve ler setennças, \\
Itso é poqrue nós não Imeos & que se lgaim praa fomarr \\
cdaa Ltera isladoa, mas a plravaa & passeagns de txteos \\
cmoo um tdoo. & que ifornmam, intruesm ou, \\
& tavelz, apnaes enttrêem. \\
\hline
\end{tabular}

Figura 2: Texto utilizado na leitura dos alunos e professores.

1 Acrescenta-se a informação de que os monossílabos compostos por até três letras, por não sofrerem alteração na ordem de disposição das letras, facilitam a leitura do texto. 
As leituras foram realizadas individualmente e em voz alta e todas foram registradas em áudio. Após a coleta desse material, foram verificados fatores como velocidade, fluência e compreensão leitora. Além da leitura do texto, os participantes responderam a um questionário, com 12 perguntas objetivas, as quais objetivaram conhecer o perfil dos leitores, com respeito aos seus hábitos de leitura, preferências e veículos de leituras. Com isso, pretendeu-se verificar a influência desses fatores externos nas habilidades leitoras.

O texto utilizado neste experimento contém 112 palavras, sendo que 10 palavras foram repetidas (de, uma, letras, pode, não, palavra, como, um, ler, leitura) e dezesseis são curtas e previsíveis (cada, única, lugar, certo, resto, qual, ordem, letras, você, pode, total, como, todo, para, textos, talvez).

$\mathrm{Na}$ tabela 1, estáo dispostas 8 das palavras, da totalidade do texto, cujo reconhecimento foi mais difícil para os participantes, ou seja, naquelas em que ocorreram mais desvios de reconhecimento. Apresenta-se também o desempenho dos 28 leitores, sendo 25 estudantes, indicados pela letra $\mathrm{E}$ (estudante) de 01 a 25, e três professores, apontados como P (professor) de 01 a 03, conforme é apresentado na primeira coluna. Também há indicação do gênero do participante. Em azul, o gênero masculino e, em rosa, o feminino. Em cada célula da tabela 1 , dispóem-se as palavras do texto experimental que foram lidas incorretamente, indicando a palavra lida em substituição à palavra escrita. $\mathrm{Na}$ última célula, informa-se a velocidade em que a leitura foi realizada.

Tabela 1 - Fluência, velocidade e exatidão no Reconhecimento de Palavras no Texto

\begin{tabular}{|l|l|l|l|l|c|c|c|c|c|}
\hline & Total & Isolada & Aquisição & Hábil & Sentenças & Ligam & Instruem & Entretêm & T \\
\hline E01 & & & & Hábito & Centenas & Igual & Instruções & ${ }^{*}$ entres & 1,5 \\
\hline E02 & & Exata & *acirção & Hábito & Certas & Igual & & *entreem & 1,0 \\
\hline E03 & Tal & & & & Centenas & & & Entrem & 1,2 \\
\hline E04 & & & *equisição & & Centenas & Guiam & Instrumentos & & 1,3 \\
\hline E05 & & & *equisição & & & & *intrusem & Entrem & 3,1 \\
\hline E06 & & & & & & & & & 2,5 \\
\hline E07 & & *isladoa & *aquici & Habitual & & Alargam & & Entrem & 1,3 \\
\hline E08 & & & & & & & & & 1,1 \\
\hline E09 & & & *equisição & & & & & Interesse & 1,4 \\
\hline E 10 & & & & & & Igualam & & & 1,4 \\
\hline
\end{tabular}




\begin{tabular}{|c|c|c|c|c|c|c|c|c|}
\hline E 11 & Tal & & Habitual & & & & Entrem & 1,3 \\
\hline E 12 & & *esquisição & & & & *intrusem & Entrem & 1,4 \\
\hline E 13 & & & & & & & & 2,0 \\
\hline E 14 & Tanto & & Habita & & & Instruções & Entrem & 2,3 \\
\hline E 15 & & & & & & & Entrem & 1,0 \\
\hline E 16 & & & Ágil & & & & Entrem & 1,2 \\
\hline E 17 & & & Apto & & & & Entendem & 0,5 \\
\hline E 18 & & & & & Algo & & & 1,0 \\
\hline E 19 & & *aquisioção & Habitual & & & *intrusiasmam & & 2,4 \\
\hline E 20 & Tão & Ocasião & & & & ${ }^{*}$ intus & Entrem & 1,0 \\
\hline E 21 & & & & & & & *enterem & 2,3 \\
\hline E 22 & Toda & *equisiç̧ão & & Centenas & & & & 1,4 \\
\hline E 23 & & & *habia & & & & Entenderem & 9,1 \\
\hline E 24 & & & & & Leiam & & & 1,3 \\
\hline E 25 & & & & & Igualam & & Entrem & 1,4 \\
\hline P01 & & & & & & & & 0,4 \\
\hline P02 & & & & & & & & 1,1 \\
\hline P03 & & & & & & & Entrem & 1,2 \\
\hline
\end{tabular}

= feminino $E=$ estudante $\mathrm{T}=$ tempo de leitura (minuto, segundo)

$\square=$ masculino $\mathrm{P}=$ professor $\quad *$ p palavras inventadas $\left(\mathrm{sem}^{*}\right.$ constam na língua $)$

A análise dos resultados organizados na tabela 1 apontam aspectos importantes sobre o processamento da leitura. Relativo ao fator velocidade, verificou-se que, para se ler um texto de 112 palavras, a média de tempo foi de 1,7 min, equivalente a $67 \mathrm{~s}$, no grupo em estudo. Logo, esta velocidade equivale a uma média de menos de duas palavras por segundo. Sete estudantes ficaram acima desta média, ou seja, precisaram de mais tempo para ler o texto, entre 2,0 min até 9,1 min. Destacam-se entre esses, dois deles, sendo que o E05 levou 3,1 min e, o E23, 9.1. Também se realça que essa leitura, embora mais lenta, não se eximiu de erros, sendo que respectivamente esses leitores cometeram de cinco a sete erros de pronúncia da palavra escrita. Os demais participantes, num total de 21 , realizaram a leitura na faixa de até $1,5 \mathrm{~min}$, equivalente a 65s. A Professora 1 (P1) foi quem leu mais rapidamente, registrando $0,4 \mathrm{~min}$, sem cometer nenhum erro de pronúncia. 
No gráfico 1, pode-se verificar o fator de velocidade na leitura, considerando estudantes e professores. Constatou-se que, relativo à velocidade, em referência à variável gênero, entre os estudantes, os meninos foram mais lentos do que as meninas.

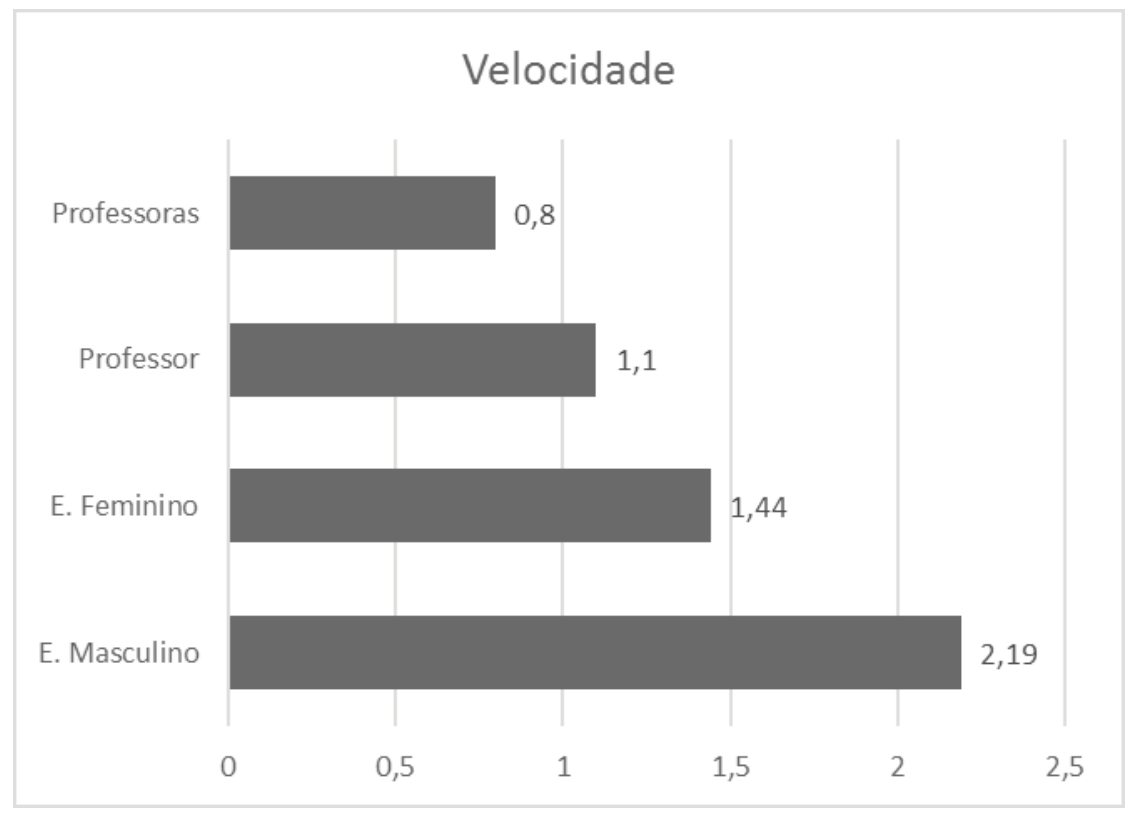

Gráfico 1: Média de velocidade.

Entre os alunos, a leitura mais rápida foi realizada pelo E17, que foi de 0,5 min, mas, quanto ao item fluência, foram registrados 5 equívocos no reconhecimento das palavras.

Relativo à fluência, apenas E14 é que apresentou baixa fluência na leitura, pois além de não ter reconhecido 04 das 08 palavras em que houve mais desvios, considerando a média dos leitores (ver tabela 1), também não reconheceu, no texto, as palavras: certo (correto), converte (convence) e passagens (paisagens). Para observar a relação entre velocidade e fluência, na leitura do E14, observa-se que seu tempo de leitura ficou relativamente acima da média, 2.3, o que já caracteriza uma leitura um pouco lenta. Esta leitora tem quinze anos de idade e nunca foi reprovada. No questionário sobre o texto afirmou 
conhecer a primeira parte do texto, bem como indicou que o nível de dificuldade do texto era fácil. Confirmou ter entendido a mensagem do texto e afirmou ter o hábito de ler também fora da escola, com preferência por livros de literatura. Quanto à discrepância entre os hábitos de leitura e o desempenho leitor de E14, talvez possa ser explicado por outros fatores ainda, os quais não foram focalizados neste estudo, mas que também intervêm no processo leitor, como o nervosismo. Também não se constitui objeto desta pesquisa averiguar, por meio de teste-diagnóstico, o fator compreensão textual. Mas, sabe-se que quando não se reconhece corretamente uma ou mais palavras, a compreensão fica, no mínimo, parcialmente comprometida.

O leitor E23, que não obteve fluência em sete das oito palavras agrupadas na tabela 1, conforme visto, fez uma leitura muito lenta, alcançando um tempo muito superior à média, que chega a ser excepcional. Para tentar compreender por que ele demorou tanto tempo para ler o texto, buscou-se analisar o perfil deste leitor. Ele tem dezesseis anos de idade, nunca foi reprovada e se avaliou como um leitor assíduo e que prefere ler livros virtuais. No questionário aplicado, afirmou conhecer a primeira parte do texto. Porém avaliou o texto como de difícil leitura e que o compreendeu parcialmente. A sua leitura lenta talvez possa ser justificada por fatores como timidez ou ansiedade ou não compreensão da atividade.

Um estudante, o E10, apresentou desempenho leitor similar ao dos professores. Ele concluiu a leitura em 1,4 minutos e cometeu apenas um erro de reconhecimento de palavras. Trata-se de um aluno de 15 anos de idade, que nunca foi reprovada e que se considera um leitor assíduo, e que tem preferência por livros virtuais. Ao responder ao questionário, afirmou não conhecer o texto e o avaliou como um texto difícil, mas que o entendeu parcialmente.

Em referência aos professores, os quais estão na faixa etária de 30 anos, todos afirmaram conhecer a primeira parte do texto. Consideraram a leitura fácil e consequentemente declararam que compreenderam a mensagem do texto. Sobre seus hábitos leitores, informaram que gostam de ler fora do trabalho e que preferem livros impressos. Destaca-se entre eles, a P01, de 39 anos. Ela realizou a leitura em menor tempo e não apresentou nenhuma dificuldade no reconhecimento das 112 palavras que compóem o texto, o que indica alta velocidade e fluência, o que consequentemente contribui para a compreensão textual. 
Como supramencionado, o texto do experimento é dividido em duas partes: 'parte provavelmente familiar' (trecho que consta na Web) e outra "inédita" (paráfrase de um parágrafo do livro de Ellis). As palavras que se destacaram por terem sido lidas com dificuldade, sendo trocadas por palavras existentes e em alguns casos por palavras não existentes na língua portuguesa, somam um total de oito palavras e, dentre elas, seis constam na parte "inédita" no texto (aquisição, hábil, sentenças, ligam, instruem, entretêm), ${ }^{2}$ corroborando com a proposição de que o fator familiaridade é decisivo para reconhecimento de palavras. No gráfico 2, podemos observar como ocorreu o nível de dificuldade destas palavras.

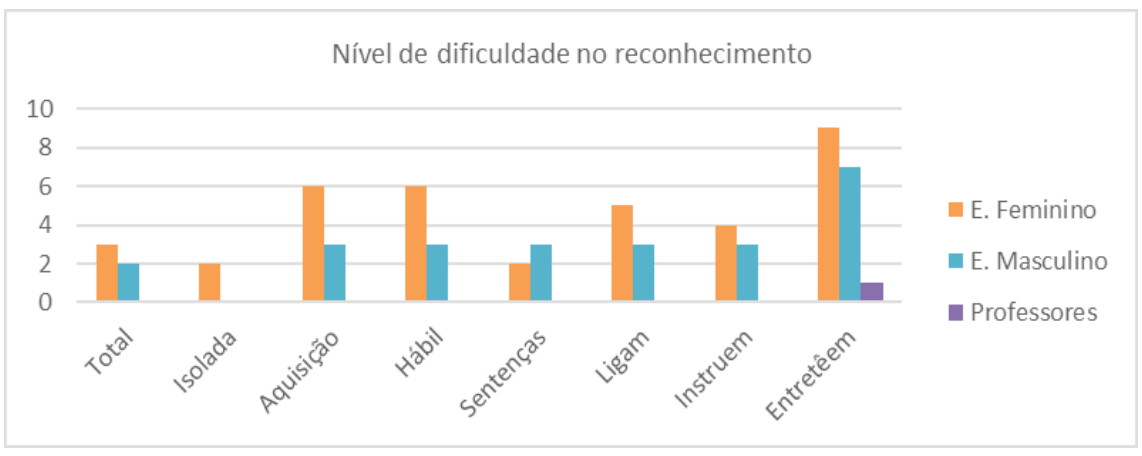

Gráfico 2: Nível de dificuldade no reconhecimento.

No gráfico 2, temos a descrição da dificuldade de reconhecimento das palavras destacadas pela dificuldade dos alunos e professores em realizá-las. Podemos verificar a distinção entre o gênero masculino e feminino e suas dificuldades com cada palavra. Assim, concluímos que as estudantes atingiram um nível maior de desvio no reconhecimento destes vocábulos, principalmente por o apresentarem em todas as palavras. Logo, foram menos fluentes que os meninos.

De acordo com Ellis (1995, p 39), um leitor capaz pode tentar uma leitura em voz alta de uma cadeia não familiar de letras e pode ser capaz de reconhecer a palavra com base em seu som, reorganizando a disposição das letras. Assim considerando, a partir desta informação, o texto do experimento

2 Na escrita da palavra "entretêm", por interesse da pesquisa, preservou-se a ortografia do texto do experimento, a qual náo foi atualizada segundo o NAO. 
de leitura representava cadeias não familiares de letras, uma vez que elas se encontravam embaralhadas, estando apenas a primeira e a última em suas reais posiçóes. Mas, lançando mão dos processos cognitivos atuantes no reconhecimento de palavras, o leitor pode reorganizá-las e realizar a leitura com relativa velocidade e fluência, conforme já descritas.

Essa reorganização se realiza com base nas informaçóes prévias armazenadas no léxico de input visual, interligando-as com o sistema semântico, para que seja feita a seleção lexical, relacionando-a com o léxico da produção da fala, nível do fonema e, finalmente, resultando na pronúncia da palavra escrita.

Portanto, quanto à seleção lexical, constatou-se que, no caso, das oito palavras em que o leitor pronunciou uma palavra diferente da que estava escrita, a troca ocorreu por vários motivos, entre outros:

a) Troca por palavras similares que estavam armazenadas no léxico mental do leitor.

(I) aqsiçãuio 'aquisição': ocasião;

(II) háibl 'hábil': hábito, habita;

(III) setennças 'sentenças' : centenas;

(IV) lgaim 'ligam': igual, alargam, guiam;

(V) intruesm 'instruem': instruçóes e instrumentos.

(VI) enttreem 'entretêm': entrem, entenderem, entendem;

(VII) ttaol 'total': tão, toda.

b) Troca por palavras mais familiares e mais frequentes que poderiam estar neste contexto:

(I) ttaol 'total: tal;

(II) háibl 'hábil': habitual, ágil, apto.

c) Troca por palavras hipotéticas por desconhecerem a palavra escrita:

(I) aqsiçãuio 'aquisição': acirção*, equisição*, equisição*, aquisioção*;

(II) intruesm 'instruem': *intrusiasmam, *intrusem, *intus;

(III) enttreem 'entretêm' : *entres, ${ }^{*}$ entreem, ${ }^{*}$ enterrem.

Por outro lado, a leitura decodificada conforme o que está escrito não garante entendimento do texto. Pode-se ler uma palavra, interligando somente o 
léxico de input visual ao de produção da fala e nível fonético. Nesse processo, as palavras não familiares aos leitores foram substituídas pelas familiares ou hipotéticas. Isso evidencia uma estratégia do leitor. No entanto, a compreensão leitora é prejudicada.

Por definição, segundo Ellis (1995, p. 39), palavras não familiares e não palavras não transmitem significado, pois sua pronúncia não foi ainda armazenada. Por isso, o léxico de input visual, sistema semântico ou léxico de produção de fala não poderiam estar envolvidos neste processamento de leitura.

Contudo, há um procedimento dentro do Modelo de Reconhecimento de Palavras que permitirá que o leitor reconheça a cadeia de letras como não familiar e que mesmo assim execute a leitura. Este procedimento encontra-se na conexão direta entre sistema de análise visual, que trata da identificação de letras e suas posiçóes, e nível do fonema, que representa os sons individuais da fala. De acordo com Ellis (1995), quando se conecta estes dois módulos, permite-se que as letras ativem os sons com os quais estão mais tipicamente associadas. Para exemplificar, observa-se o que ocorreu com a palavra entretêm no experimento de leitura. No texto, a palavra estava escrita da seguinte forma: enttreem. Ao recuperarem o som das duas primeiras letras, onze dentre os vinte e oito leitores participantes pronunciaram: entrem.

Este procedimento descrito que se refere ao caminho que liga a letra ao seu respectivo som não leva em consideração se as letras em questão são pertencentes a palavras familiares ou a não palavras, por isso recebe o nome de "procedimento não lexical" ou via "sublexical" (ELLIS, 1995). Esta via é responsável pelo fenômeno onde o leitor é capaz de pronunciar uma palavra aparentemente desconhecida.

Por fim, realça-se que dentre as oito palavras em que houve dificuldade no reconhecimento, três ocuparam o nível mais alto na escala de dificuldades, as quais são: "aquisiçâa”, "igualam” e "entretêm" (18 vezes); seguida por "isolada" e "hábil" (16 vezes) e por "sentenças" (13 vezes). As palavras "total" e "instruem" foram substituídas por 10 participantes. Conclui-se que os desvios de pronúncia ocorreram de maneira concentrada e incidiram em palavras não familiares ao léxico dos leitores; de menor frequência na língua; de aquisição mais tardia, por serem mais frequentes na fala e na escrita culta da língua. 


\section{Considerações finais}

O estudo realizado neste trabalho refletiu sobre os processos cognitivos envolvidos no reconhecimento de palavras a partir do modelo teórico proposto por Ellis (1995). Foram descritos e analisados os fatores que influenciam no reconhecimento hábil das palavras.

Conforme exposto, verificou-se que as palavras familiares e palavras aprendidas em tenra idade proporcionam facilidade para que se acesse o sistema semântico e o léxico de produção da fala. Constatou-se também que a decisão lexical que o leitor faz ao pronunciar uma palavra pode ser determinada a partir dos próprios sons iniciais que ele emite, os quais se relacionam com palavras similares, armazenadas no seu léxico de input visual, entre aquelas mais frequentes na língua, como no caso enttrêem 'entretêm', que foi pronunciada pela grande maioria como "entrem", ou de seu (des) conhecimento da ortografia da palavra, também armazenada em seu léxico de input visual, como ocorreu com a leitura do grupo de letras "setennças" (sentenças), substituída por centenas.

Os processos cognitivos ativados no processo leitor são desencadeados pelo mecanismo de reconhecimento da palavra. Este, por sua vez, sofre a influência de fatores, conforme descritos, os quais determinam a velocidade, a fluência em que a leitura se realiza e a compreensão do texto. Espera-se que este estudo contribua para a ampliaçáo do conhecimento a respeito dos processos cognitivos ativados durante a leitura e que sirvam de orientaçáo para uma prática pedagógica mais eficiente na perspectiva da formação de leitores competentes.

\section{Referências}

BESNER, Derek. HUMPHREYS, Glyn W. Basic process in reading - visual word recognition. New Jersey: Lawrence Erlbaum Associates, Publishers, 1991. ELLIS, A. W. Leitura, escrita e dislexia: uma análise cognitiva. Porto Alegre: Artes Médicas, 1995.

HUMPHREYS, Glyn W. BRUCE, Vicki. Visual cognition: computational, experimental and neuropsychological perspectives. East Sussex: Lawrence Erlbaum Associates, Publishers, 1989. 
FODOR, Jerry. The modularity of mind. Cambridge, Massachusetts: The MIT Press, 1983.

GILHOOLY, Kenneth. LOGIE, Robert. Word age-of-acquisition, Reading latencies and auditory recognition. 1981. Current psychology research, 1, 251-262. SENNA, Fernanda Duarte. Acesso e representação lexical na produção de afásicos sob a ótica da fonologia de uso. 2013. Tese (doutorado em Linguística), Programa de Pós-graduação em Linguística, Universidade Federal do Rio de Janeiro, 2013.

\title{
COGNITIVE ANALYSIS OF THE READING IN THE PROCESS RECOGNITION OF WORDS
}

\begin{abstract}
The reading is a hard activity to being developed, demanding an extensive learning. On this perspective, the objective is describe and analyze the abilities of recognition of words through of Model of Recognition of the Words, proposed by Ellis (1995). The results could contribute to a more efficient pedagogical practice in the formation of reading competence.

KEYWORDS: recognition of words; reading comprehension; cognitive processes.
\end{abstract}

Recebido em: 30/10/2015

Aprovado em: 11/03/2016 